\title{
Conjunctival Botryomycoma: A Case Report
}

\author{
M. Khamaily, J. Brahim Salem, H. Brarou, I. Tarib, S. Dahi, M. Bouchaar, R. Zerrouk, \\ Y. Mouzari, F. El Asri, K. Reda, and A. Oubaaz
}

\begin{abstract}
The fleshy telangiectatic bud or pyogenic granuloma is a tumor-like lesion that develops from chronic inflammatory situations of the conjunctiva or the eyelid. The chalazion represents one of the most frequent of these situations. We report the case of a child who presented, after a chalazion, a pyogenic granuloma, treated by surgical removal.
\end{abstract}

Index Terms - conjunctival tumor, pyogenic Granuloma.

\section{INTRODUCTION}

Botryomycoma, also known as pyogenic granuloma or lobulated capillary hemangioma, is a benign tumor of vascular origin in the superficial dermis, but hypodermic and mucous forms have also been reported [1].

Conjunctival involvement is rare, it is typical of childhood [2], which occurs in the form of a benign inflammatory fibrovascular proliferation, often occurring at the level of the palpebral conjunctiva in reaction to an attack (chalazion or previous surgery) or trauma [3].

This conjunctival tumor remains painless, bright red in color with smooth surface bleeding easily, often pedunculated [4], of favorable evolution under topical anti inflammatory treatment which can be attempted first, in case of incomplete regression, surgical excision is the treatment [5].

Argon laser treatment has not been shown to be effective on this type of tumor [6].

\section{CASE REPORT}

We report the case of an 8-year-old child who presented to the consultation for a painless lump of the upper palpebral conjunctiva that bleeds when the eyelid rubs (Fig. 1).

The patient reports a chalazion recurring in the same place more than 3 months ago and the visual acuity was 20/20 without correction, with no other associated signs.

We tried to take medication based on topical corticosteroid therapy, but without results, we then performed the surgical excision under local anesthesia.

Published on July 1, 2020.

M. Khamaily, Mohammed V University of Rabat, Morocco.

(corresponding e-mail: mehdi.khamaily gmail.com).

J. Brahim Salem, Mohammed V University of Rabat, Morocco.

I. Tarib, Mohammed V University of Rabat, Morocco.

S. Dahi, Mohammed V University of Rabat, Morocco.

M. Bouchaar, Mohammed V University of Rabat, Morocco.

R. Zerrouk, Mohammed V University of Rabat, Morocco.

Y. Mouzari, Mohammed V University of Rabat, Morocco.

F. El Asri, Mohammed V University of Rabat, Morocco.

K. Reda, Mohammed V University of Rabat, Morocco.

A. Oubaaz, Mohammed V University of Rabat, Morocco.
The post-operative follow-up was without particularities (Fig. 2) and without sign of recurrence at 6 months, and the pathology study did not show signs of malignancy.

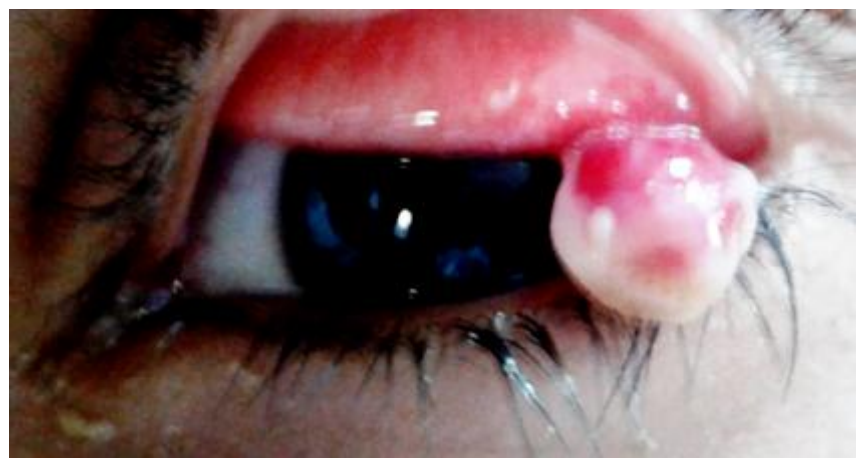

Fig. 1. Pedunculate conjunctival tumor of the left upper eyelid in an 8-yearold child

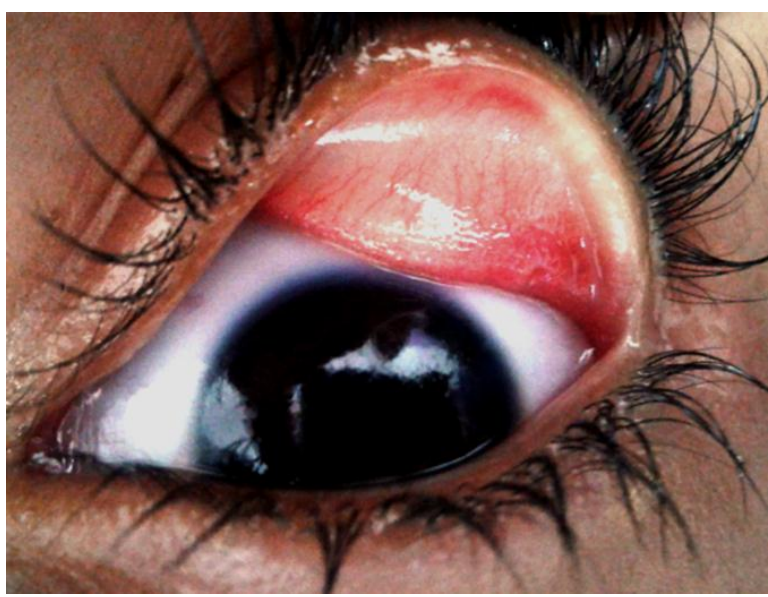

Fig. 2. $48 \mathrm{~h}$ after surgical treatment.

\section{REFERENCES}

[1] R. R. Fortna, J. M. Junkins-Hopkins, "A case of lobular capillary hemangioma (pyogenic granuloma), localized to the subcuta-neous tissue, and review of the literature", Am J Dermatopathol, vol. 29, pp. 408-11, 2007.

[2] R. L. Lin, C. K. Janniger, "Pyogenic granuloma", Cutis, vol. 74, pp. 229-33, 2004.

[3] J. Peter et al. "Conjunctival and corneal tumors", Essentials of ophthalmic oncology, 2009, p. 51-64.

[4] J. A. Shields, C. L. Shieds, "Atlas of eyelids and conjunctival tumors in: part II, tumors and pseudotumors of the conjunc-tiva", Philadelphia: Lippincott Williams and Wilkins, p. 200-329, 1999.

[5] C. L. Shields, J. A. Shields, "Tumors of the conjunctiva and cornea", Surv Ophthalmol, vol. 1, pp. 3-24, 2004.

[6] J. M. Ruban, "Traitements des affections palpébrales au laser", Argon.J Fr Ophtalmol., vol. 26, pp. 88-91, 2003. 